\title{
Development of a Knowledge-Based Engineering Framework for Modeling Aircraft Production
}

\author{
Julia Page Risueño*, Björn Nagel ${ }^{\dagger}$ \\ German Aerospace Center, DLR - Institute of System Architectures in Aeronautics, Hamburg, Germany
}

\begin{abstract}
Production modeling and cost estimation are among the main drivers in contemporary approaches to design aircraft and aircraft components. However, the existing methodologies presented in academia to evaluate these disciplines are not widely used in the industry because of (a) black-box behavior of the current production modeling systems, (b) lack of connection between the production modeling systems and the design process, (c) elevated cost and time needed to implement the methods, (d) confidentiality of production information, and (e) resistance to change the working methods.

The research presented in this paper proposes a methodology that aims to overcome these limitations by combining knowledge-based engineering with semantic web technologies in the modeling of aircraft production processes. The methodology is realized by a generic, flexible, adaptable and reusable framework for modeling production, which can evaluate the influence of different production concepts, to quantify the interactions between production processes and aircraft design and to conduct studies of performance, and production costs.
\end{abstract}

\section{Introduction}

During the past decades there has been a shift in the aerospace industry's main drivers towards the reduction of overall cost and lead-time [1]. It is estimated that over 30\% of the total aircraft cost is incurred during production [2], whereas $80 \%$ of this cost is determined during the conceptual design stage [3], when engineers have more freedom in their design decisions. Consequently, engineers are starting to consider the implications of their decision-making on production early in the design.

Although some progress has been made in the development of methodologies to model production of aerospace vehicles [4-6], the level of implementation of these methodologies in industry is limited. Members of the industry still use traditional methods to model production, which are mostly manual and dependent on the engineer's experience. This makes the design process time-consuming, and therefore, engineers can only check a simplified set of cases before the release of the production plan [6].

In view of this situation, the following points likely have an impact on the reasons of why the academic advancements are not used in industry: (a) black box behavior of the production modeling systems [7], (b) lack of connection between production modeling and the design process, (c) elevated cost and time required to implement in the industry the methods proposed in academia [8], (d) confidentiality of information about processes necessary for modeling production, and (e) resistance to change the current methods [9].

The research presented in this paper focuses on the development of a methodology that seeks to mitigate these drawbacks. The methodology is based on the combination of knowledge-based engineering (KBE) and semantic web technologies (SWT), and leads to a framework capable of modeling aircraft production processes. The first step to achieve this is to identify the requirements of the framework, which are determined from the challenges and limitations found in the previous research and experiences. Hence, the next section explains the challenges of the current methodologies employed in the modeling of aircraft production. Section III deduces the main requirements and proposes a structure for a production modeling framework. This modeling framework has been employed in Section IV to demonstrate its application in the production of an aircraft fuselage. Finally, a conclusion and an outlook to future work are drawn.

\footnotetext{
* Research Associate, Cabin and Payload Systems

${ }^{\dagger}$ Founding Director, Institute of System Architectures in Aeronautics
} 


\section{Challenges of the current methodologies}

\section{A. Traditional method}

The design and production planning of a product is generally carried out apart from each other: the design engineers first generate a design before the production engineers create the production plan and provide feedback about possible modifications that will make the assembly and manufacturing process easier. The design engineers then redesign the product to satisfy those needs in an iterative process. This cycle is repeated until a competitive design is achieved, implying additional challenges such as a further need for optimization, lack of integration of design and production, dependence of the expertise of the engineers, and high development time. Oftentimes, the cycle does not converge due to the lack of time assigned to the design process.

\section{B. Knowledge-based engineering methodologies}

To solve the aforementioned limitations, knowledge-based engineering has been suggested to assist engineers when modeling aircraft production [10]. KBE is a technology that automates repetitive design tasks by capturing, retaining and reusing design knowledge, resulting in a reduction of development time and cost. KBE therefore provides several advantages, namely, increase of creative design time, reduction of the number and duration of the design iterations and improvement in collaborative design to ultimately reduce development time [7].

Efforts have been made in this direction and several authors have presented work that combine KBE with manufacturing modeling, such as Zhou et al. [4], Pullan et al. [11], Wang et al. [12] or Tan et al. [13]. However, these authors presented use-specific applications that are not generic and have only been validated for a particular example. Furthermore, their models were implemented for simpler cases than an aircraft component or a complete aircraft, whose design and production is fairly distinct not only because of its complexity but also because of its weight, dimensions or resources needed; aspects that significantly affect production.

Additional research exists in the field of cost estimation using KBE, as is seen in the work of Van der Laan [14], Zhao et al. [15] or Quintana-Amate et al. [5]. Nevertheless, these models compute cost without having a complete overview of the production processes, since cost is estimated using cost estimation relationships (CERs), which are mathematical expressions that relate cost to independent variables and are usually based on empirical data.

Most of the methods that connect KBE with manufacturing modeling do not include assembly as a manufacturing process. Despite the fact that assembly modeling has been widely studied, the work in the field of aeronautics is limited. The existing research about aircraft assembly modeling $[6,16,17]$ was not connected to the design process, meaning that the production systems did not provide any feedback on how a change in the design will affect the assembly sequence or processes. In fact, most of the existing KBE systems that model production or estimate cost are not completely integrated with the design process, therefore limiting collaborative design.

All the previously mentioned research shares the same major limitation: the developed KBE systems acted as black boxes, where the knowledge is stored inside the application. Consequently, the user is unaware of the knowledge and reasoning behind the solution. To avoid this black box behavior, Vergahen et al. [7] suggested the need of moving away from case-based projects towards methodology-guided projects, which will help to prevent the knowledge loss and misuse. In this line, Sanya and Shehab [18] suggested the use of semantic web technologies in order to separate the system knowledge from the system execution, and developed a methodology to create ontology-based KBE frameworks. According to $\mathrm{W}_{3} \mathrm{C}^{*}$, semantic web technologies provide a common framework that allows sharing and reusing data across applications and enterprises. This will loosen the dependency between the knowledge and its execution, thereby increasing the maintainability and protecting the knowledge.

The presented research validated the applications by only evaluating the reduction in design time, but did not evaluate if the obtained results were realistic. In most cases, the systems did not allow the exploration of the design space, which is believed to be of great importance, since it will enhance the understanding of how changes in the design will affect the production process and cost.

\section{Practical challenges}

Besides the aforementioned challenges, there exist practical problems that arise when implementing KBE applications. These include the high costs associated to the implementation of KBE systems, the confidentiality of information or the resistance to change of the engineers.

\footnotetext{
*World Wide Web Consortium: https://www.w3.org/standards/semanticweb/
} 
Implementing a KBE system requires high levels of skill and time. Although more time is required during the initial stage of the design, it will pay off later in terms of reduced amount of repetitive tasks to be performed and engineering changes once the design has been released into production, lowering the production cost in the long run [8].

Secondly, KBE systems need knowledge and information that companies are not willing to provide. This is especially true for aircraft production and cost estimation, since the data is sensitive. Therefore, there should be a clear separation between knowledge and its execution, which will enable the aircraft production modeling systems to be flexible and adaptable so that companies can fill in or expand the production knowledge. To satisfy this requirement, it is highly important that the KBE systems are not made for specific cases, but that they are generic.

Finally, cultural issues make engineers reluctant to change their practices because of lack of trust in or understanding of new technologies, or considering them as a threat $[9,19]$. The production modeling system should be developed taking into account the preferences and working methods of the future users, and making it easy to add or modify knowledge in an understandable user interface (UI) with a simple common language.

In summary, there is a need for a generic system that models aircraft production, where knowledge and its execution are separated and the practical aspects of the system's development are taken into account. Potential users of KBE systems often do not have KBE competence, or personal willingness to share knowledge. Consequently, the purpose of this research is to develop a generic KBE system to model aircraft production using semantic web technologies, in order to allow the evaluation of the interactions between design and production, while considering the practical issues that may arise in industry.

\section{Framework requirements and structure}

The main challenges to overcome when creating a production modeling KBE system have been summarized in Table 1, which includes also a connection with the corresponding requirements.

Table 1 Challenges of the previous research and requirements of this research.

\begin{tabular}{|c|c|}
\hline Challenges & Requirements \\
\hline $\begin{array}{l}\text { 1. Black-box behavior: specific KBE systems for specific } \\
\text { examples }\end{array}$ & 1. Reasoning behind the solution easily understood \\
\hline 2. Not connected with design process & 2. Easy integration with design process \\
\hline $\begin{array}{l}\text { 3. Assembly or manufacturing modeling separated of each } \\
\text { other }\end{array}$ & $\begin{array}{l}\text { 3. Consideration of both assembly and manufacturing inside } \\
\text { the production process }\end{array}$ \\
\hline 4. Lack of design space exploration & 4. Validated results and easy integration with design process \\
\hline 5. Cost computed using CERs & 5. Cost estimation using bottom-up methods and CERs \\
\hline 6. High cost to implement KBE system & $\begin{array}{l}\text { 6. Reusable and generic system, so that the investment cost } \\
\text { is worthwhile }\end{array}$ \\
\hline 7. Knowledge and information required & $\begin{array}{l}\text { 7. Flexible and adaptable system, which will facilitate the } \\
\text { companies to use the tool with their own knowledge. Addi- } \\
\text { tionally, the use of SWT will help to protect the knowledge } \\
\text { and increase maintainability. }\end{array}$ \\
\hline 8. Cultural issues & $\begin{array}{l}\text { 8. Increase usability: } \\
\text { - Easy to modify or add information to the tool } \\
\text { - Graphical user interface }\end{array}$ \\
\hline
\end{tabular}


From these requirements, a framework to model production processes has been developed. This framework, named Manufacturing and Assembly Modeling Tool (MAMOT), consists of three parts as shown in Fig. 1: (A) the knowledge module, (B) the assessment engine, and $(\mathrm{C})$ the inference engine.

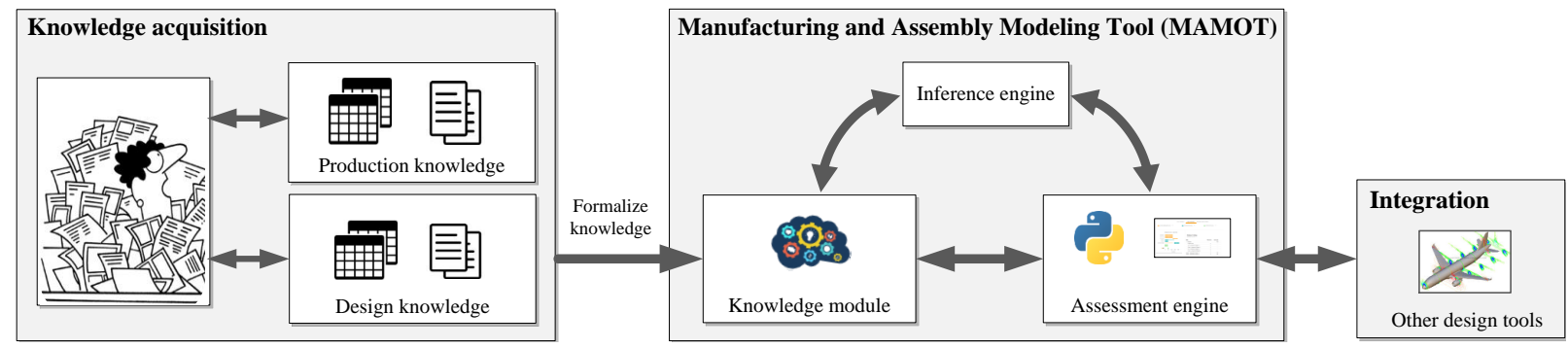

Fig. 1 Framework architecture of MAMOT.

\section{A. Knowledge module}

The knowledge module consists of ontologies and rules, which represent formal knowledge and are expressed following the W3C standards using Web Ontology Language (OWL) and Semantic Web Rule Language (SWRL) respectively. While the ontologies contain all the information regarding the manufacturing and assembly processes, the rules express the logic that will help in the decision making process.

In the scope of this research there are two types of ontologies: (a) the meta-ontology, which is a meta-model that defines the different classes and their relations, and (b) the process ontologies, which are instances of the main ontology. Figure 2 depicts a part of the main production ontology, where a Component can have one or multiple ProductionProcesses which are executed in a ProductionLine. A ProductionLine is defined by Stations that are composed of Operations. These can also have sub-operations. With this approach any production process can be defined with as much detail as desired. This is illustrated in an example in Fig. 3, where the Component Stringer has two possible ProductionProcesses: RollForm and Extrusion. Each process has a ProductionLine with several Stations and Operations. Both the stations and operations can be linked to other stations and operations with the relation hasNext. For example, Prepare tools should be performed before the Cut operation. When all the information is available, MAMOT can com-

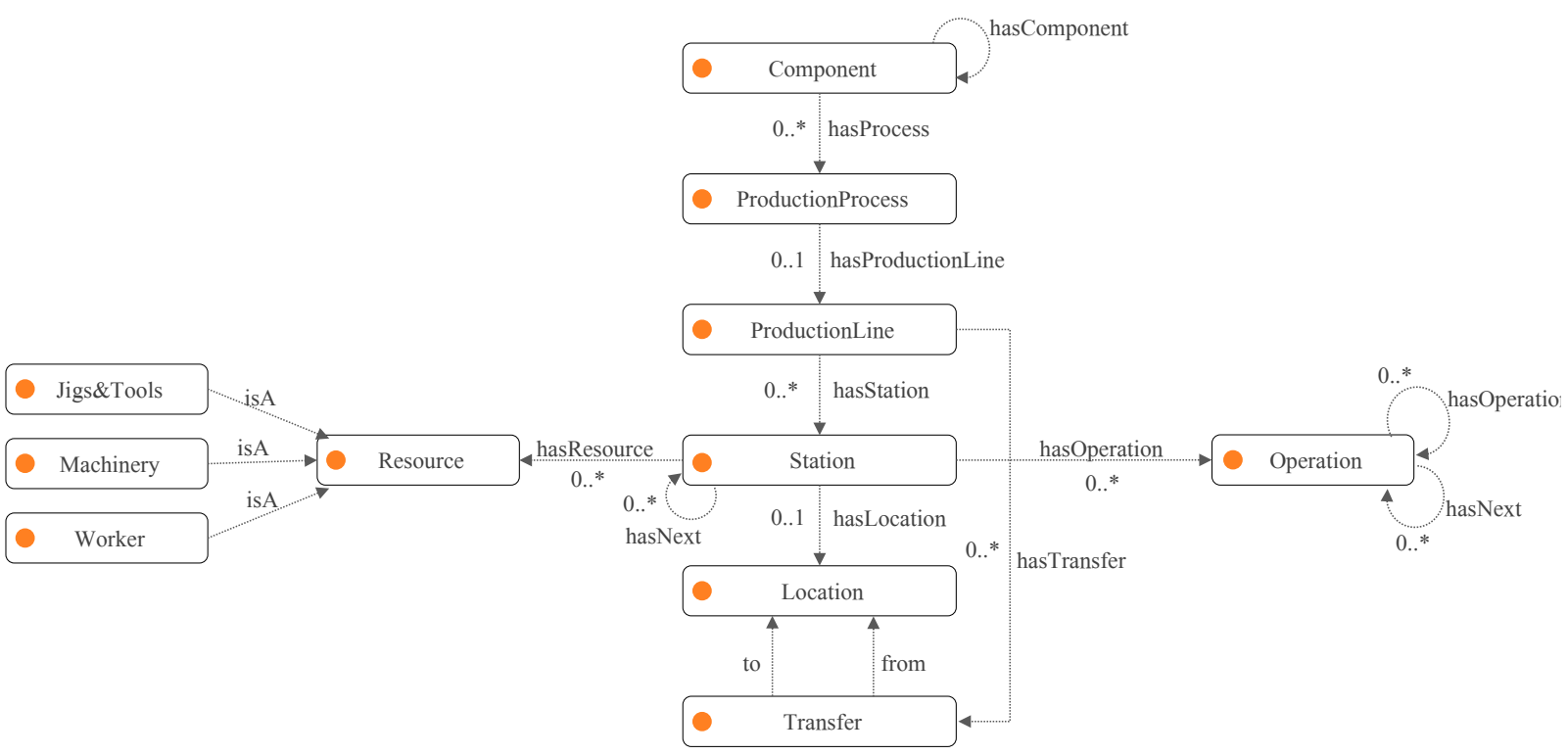

Fig. 2 Meta-ontology defining classes and class relationships. Data properties have not been included. 
pute the production cost considering all the stations and operations. Alternatively, when not enough data is provided, the ProductionProcess or Station could carry empirical information about the total time and cost.

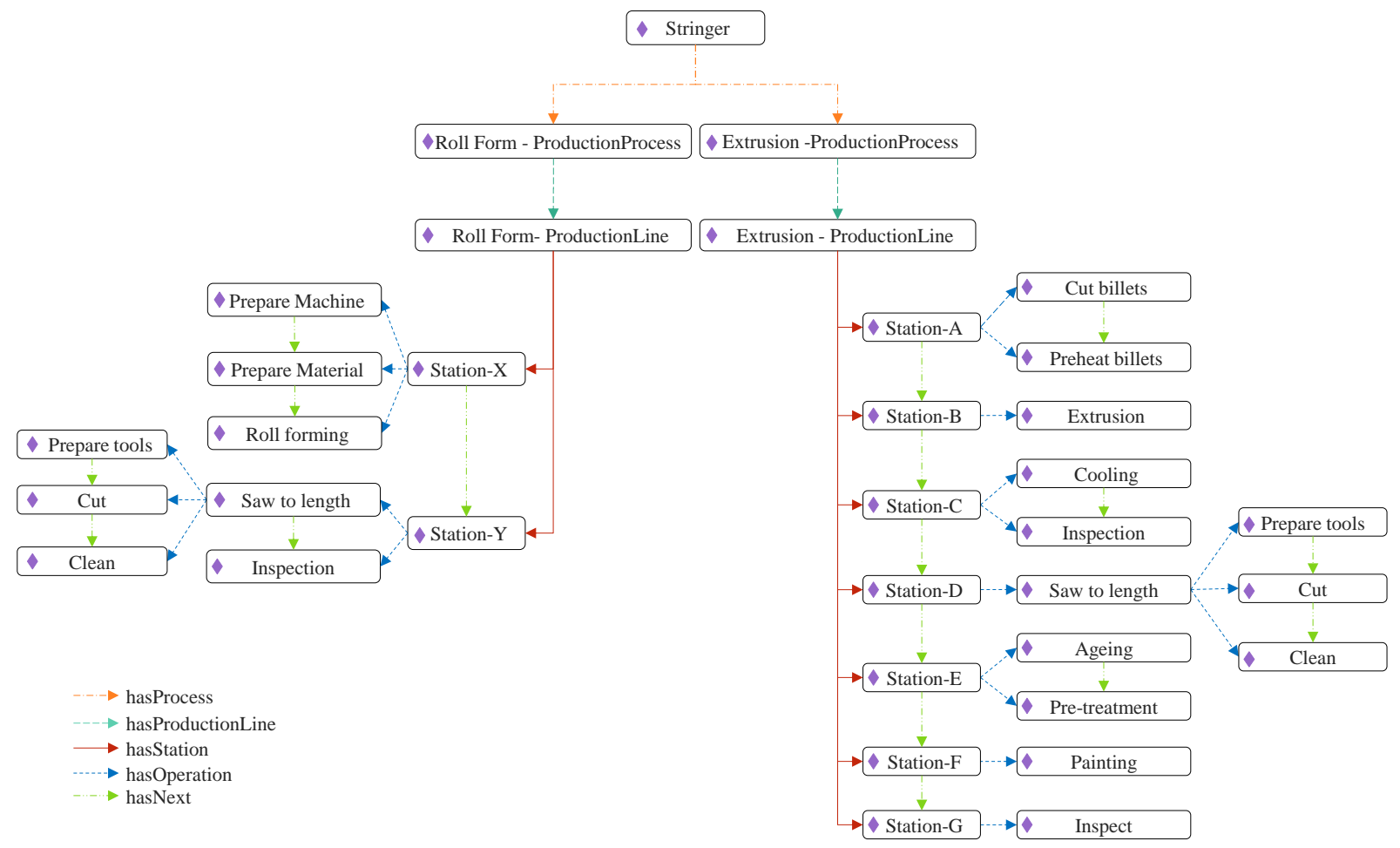

Fig. 3 Example of a production ontology for the production processes of Roll-forming and Extrusion. A Stringer can be produced by any one of these processes, which are inferred using the SWRL rules.

The ontologies are integrated with rules in SWRL to express first order logic, like the selection of the appropriate production processes. While the ontologies give the description of the different production processes, the rules help selecting which process should be used, as shown in Table 3.

Table 3 Example of a SWRL rule.

\begin{tabular}{ll}
\hline SWRL & If-then statement \\
\hline Component $(? \mathrm{c}) \wedge$ hasMaterial(?c, Aluminium $) \wedge$ hasLength(?c, & IF: a component $\mathrm{C}$, is made of material Aluminium, has a \\
$>500 \mathrm{~mm}) \wedge$ hasThickness(?c, $<10 \mathrm{~mm})$ & length greater than $500 \mathrm{~mm}$ and has a thickness lower than \\
& $10 \mathrm{~mm}$ \\
& THEN: the manufacturing process of that component is roll \\
& form
\end{tabular}

Due to the nature of the if-then statement, a component could have several production processes, which allows to explore all the possible production processes. An example is shown in Fig. 3, where a stringer can be manufactured with roll-forming or extrusion processes.

\section{B. Assessment engine}

The assessment engine acts as a connection between the production knowledge (stored in the ontologies and rules) and the design process. This engine, which is the core of MAMOT, is programmed in Python ${ }^{\dagger}$ and has a web-based user interface. It computes the production lead-time and cost of each component according to the production lines and

\footnotetext{
†https://www.python.org/
} 
stations described in the ontologies, and generates the operation sequence that later on will derive the manufacturing dossier.

This engine employs directed graphs to create the right station sequence in the production lines and to generate the operation sequence. Figure 4a shows a station graph for a production line built using the information given in the ontology. From this graph, we can generate the lead-time graph (Fig. 4b), where a station that has ingoing edges cannot start until all the previous stations are concluded. In the case shown in Fig. 4, Station D cannot begin until both Station $C$ and Station $E$ have finished. Similarly, Station $C$ cannot start until Station $A$ and $B$ have been completed.

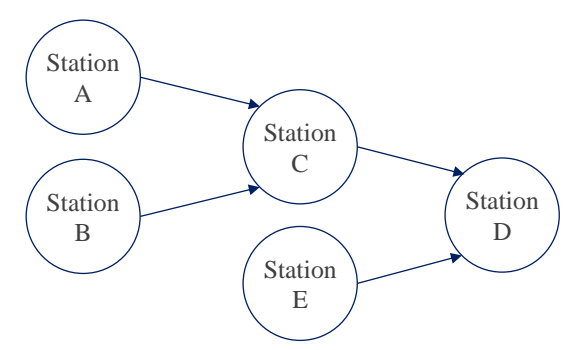

(a) Directed graph of the stations of a production line.

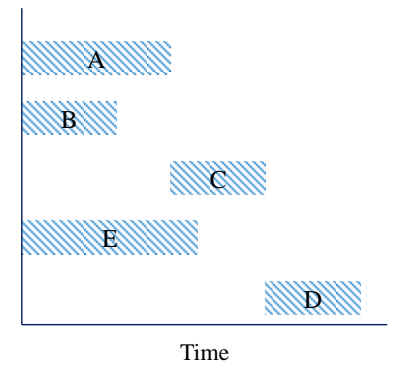

(b) Lead-time graph for a production line.

Fig. 4 Station sequence creation for a specific component using directed graphs.

The time required by each station is calculated with the time needed to perform all its operations. Figure 5 illustrates how MAMOT generates the operation sequence. The graph on the left shows a directed graph with the operations ordered following the knowledge from the ontologies. These operations are then instantiated by the assessment engine according to the specific station and the specific components that are being produced in that station. For example, the operations represented in Fig. 5a are instantiated in Fig. 5b for two components (Stringer-1 and Stringer-2). The operation Prepare tools has to be only performed once, while the operations Cut and Clean have to be carried out for each component separately. From this graph, the engine extracts the operation sequence using a path-finding algorithm.

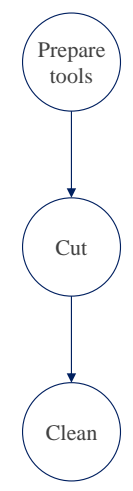

(a) Definition of the operations.

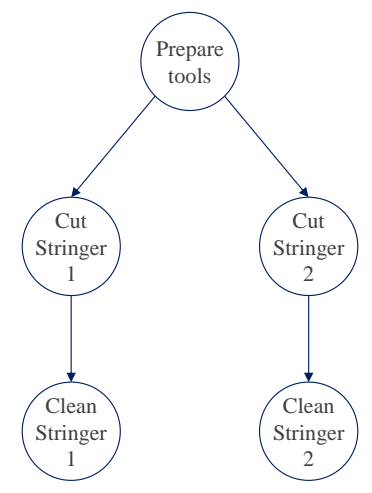

(b) Instantiation of the operation for specific components.

Fig. 5 Operation sequence examples: (a) generic description of the operations; (b) specific description of the operations for unique components.

The assessment engine also includes a fidelity ${ }^{\ddagger}$ translator in order to make the system capable of multifidelity analysis. It considers one level of fidelity in the production modeling system while allowing the user to define inputs at various fidelities. Consequently, modeling aircraft manufacturing and assembly will be possible at different design stages, enabling a more agile and flexible design process.

\footnotetext{
†The level of fidelity is defined by Gross [20] as "the degree to which a model reproduces the state and behavior of a real world object, feature or condition, i.e., it is a measure of the realism of a model".
} 


\section{Inference engine}

Both the knowledge module and the assessment engine interact with an inference engine, which is used to execute the logic rules, deduce information from the ontology and assist in the selection of appropriate production processes. For this research, the Java-based reasoner Pellet ${ }^{\S}$ has been selected since it can be operated using Python.

Figure 1 also includes the knowledge extraction and formalization phases prior to the deployment of the framework. The production knowledge is mostly held implicitly by the engineers or collected in reports and literature. In order to semantically link and formalize the scattered production knowledge, it has first to be extracted, organized and stored, which in turn facilitates the reuse and maintenance of knowledge. The knowledge acquisition and formalization has to be performed only once for a given process to populate the ontologies and rules. The formalized knowledge has to be updated when changes or additions in the production process occur. This will allow different users to have separate ontologies and rules, thus detaching the confidential information from the framework and protecting their knowledge.

While formalizing knowledge is a time consuming task, it will pay off thereafter by automating many repetitive tasks and avoiding engineering changes, since design modification and production modeling will be tied together. It is also worth noting that some companies, such as Synergeticon ${ }^{\text {II }}$, are working on algorithms using pattern recognition to semi-automate knowledge formalization from documents.

Finally, MAMOT will be connected with aircraft design tools, allowing to study the interactions between production and design processes and to explore the design space in order to achieve optimized design solutions. This will be accomplished by an integration of the production framework and the different design tools due to the modularity of the $\mathrm{KBE}$ system and the use of overall aircraft design (OAD) parameters in production modeling.

\section{Application: production modeling of an aircraft fuselage}

In order to demonstrate the operation of MAMOT, this section presents two examples of the production of an aircraft fuselage. The first example considers the manufacturing of the fuselage stringers (see Fig. 6a), while the second shows the assembly of a fuselage section (Fig. 6b).

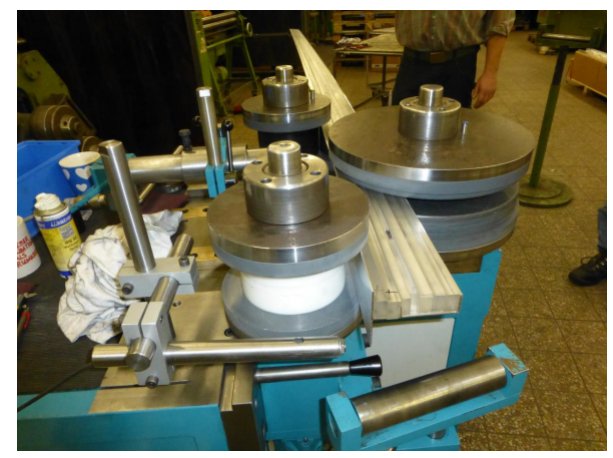

(a) Roll-form production process of the stringers.

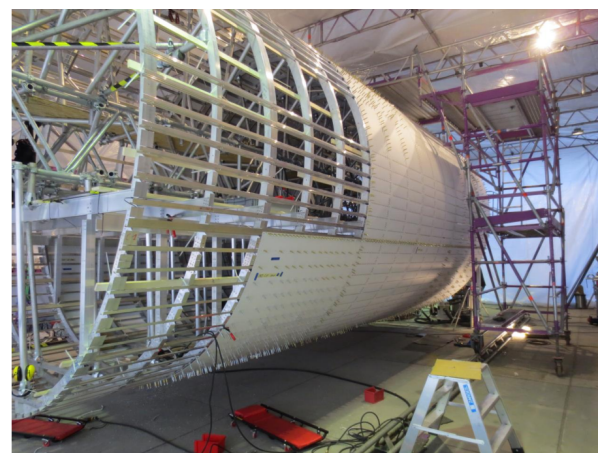

(b) Fuselage assembly of the cabin mock-up.

Fig. 6 Examples of the production of a fuselage: (a) detail of stringers manufacturing; (b) fuselage assembly. Images courtesy of Mechakustik" .

Figure 7 shows the diagram flow of MAMOT, as well as the relation between its modules. Once the production knowledge is formalized through ontologies, the user can provide the design input with Python or OWL. If the user decides to define the product hierarchy and design with Python objects, MAMOT will translate this input to OWL (1) to be able to extract the production process of each component using the inference engine (2) (3). After, the design is translated back to Python (4), where assessment engine generates the production line for each production process (5) and the operation sequence for each station considering the components manufactured or assembled at the station (6). If the user decides to give the input in an ontology, step (1) is not required and the tool will start from step (2).

\footnotetext{
§https://www.w3.org/2001/sw/wiki/Pellet

Thttps://synergeticon.com/

"http://mechakustik.de
} 


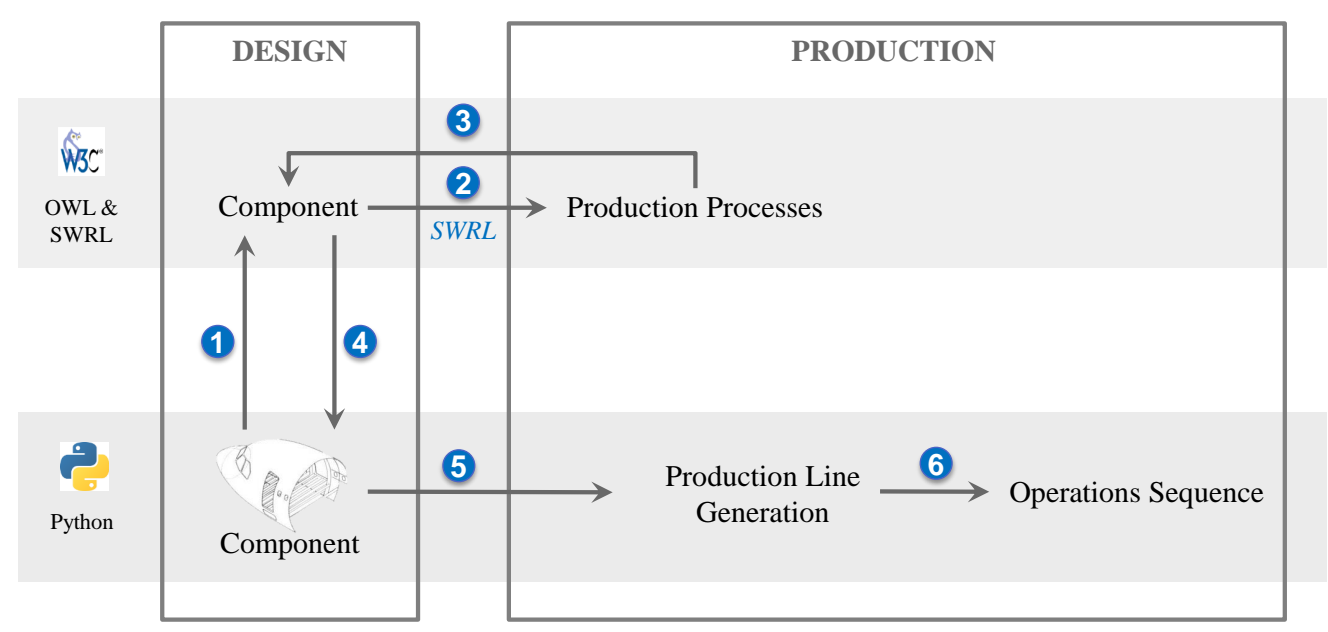

Fig. 7 Diagram flow of MAMOT with the relation between its modules.

The input ontology for both examples is shown in Fig. 8, which corresponds to the AVACON aircraft [21]. In this graphical representation of the ontology only the product hierarchical structure has been displayed, using the has Component relationship. The ontology has other relationships concerning geometry, cost, weight, etc. that have not been shown in the figure to avoid cluttering. The description of the aircraft is more detailed for the fuselage than for the rest of the components. This means that for the fuselage the production can be modeled in more detail than for the other parts.

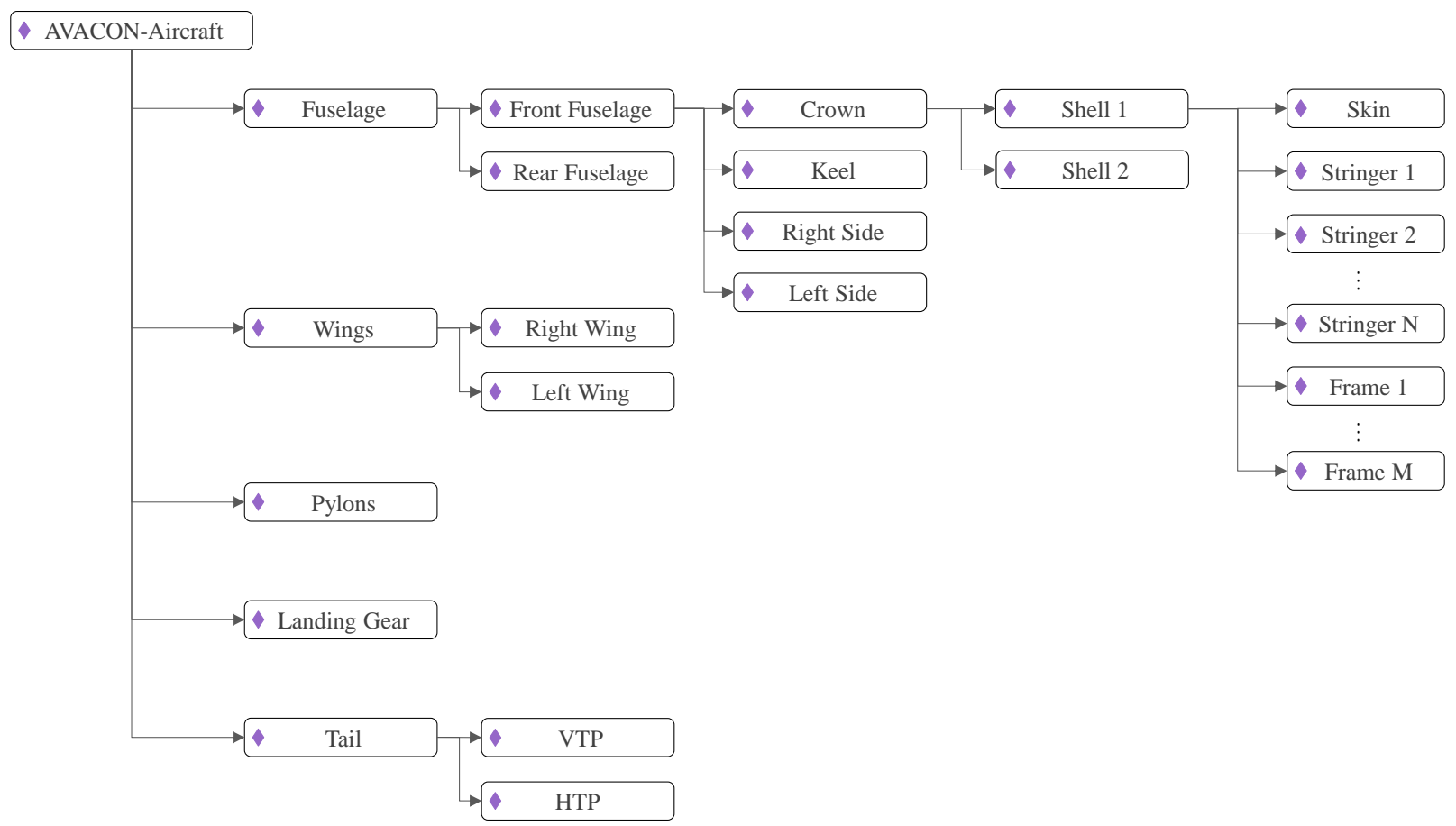

$\rightarrow$ hasComponent

Fig. 8 Input ontology of the design for the examples showing only the hasComponent relationship. 
MAMOT allows to explore the different production processes for the different components and give instantaneous feedback of changes in the design. The results obtained with MAMOT can be visualized in the UI, which is shown in Fig. 9. On the left side of the UI, the user can navigate through the product and production hierarchies and change the input values. The results of MAMOT are displayed on the right part of the UI, where the user can explore the cost overview, time overview or manufacturing dossier. The cost overview tab displays a table with all the components and its associated cost; the time overview tab allows to explore the production line, stations and operations; and the manufacturing dossier tab gives the operations to be performed to each component to produce the final product. The figure shows the cost overview with the product hierarchy and the cost and weight per component. MAMOT enables the computation of the production cost with different fidelity levels. The more information is given, the more detailed the computation is. This implies that a component can have a cost based on an input value, a user-defined cost estimation relationship (CER) or derived from the production process. Similarly, the production process can compute the time based on a value assumed to the stations or by partially or completely describing the operations involved in each station. If a component is an assembled component (produced by joining two or more components together) then the cost is the accumulation of the individual components plus the assembly cost.

For the example of the fuselage assembly, its cost is computed as an assembled component, and its total cost is the cost of all its sub-components plus the assembly cost. Since not enough information about the components was given, the assembly cost is computed using a CER instead of the production operations.

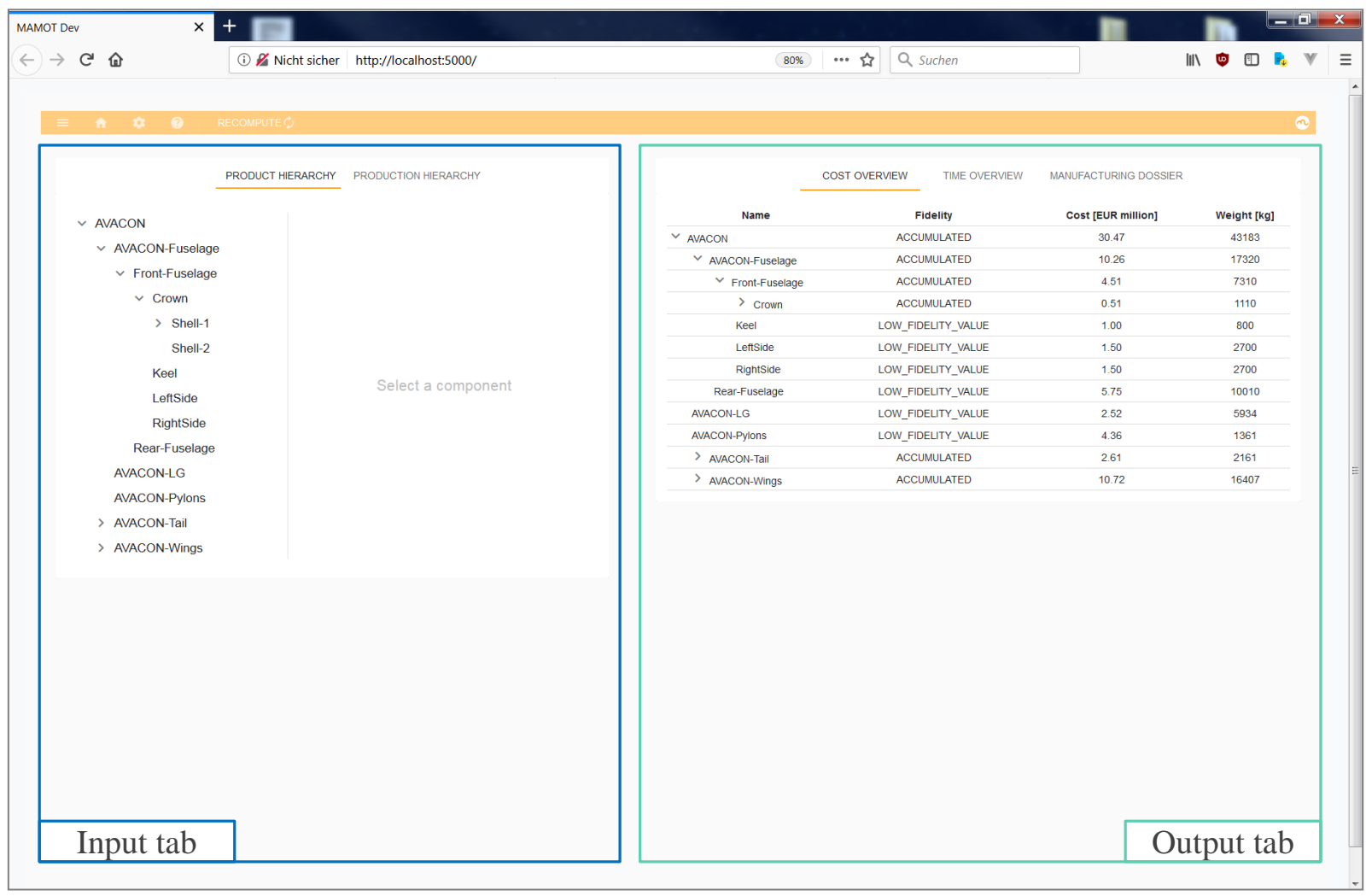

Fig. 9 User interface.

Figure 10 shows the time overview tab, where the user can select the different production processes available for the computation of the total lead-time (A). For each process, the components that are manufactured by that process can also be selected (B). In the example, only Stringer-1 and Stringer-2 have been considered. The production line lead-time graph is plotted according to those inputs (C). In the graph, we can see the order of the different stations and the critical path. However, this is still in implementation and the transfer and transport operations are not included yet. Upon clicking on a station, the operation sequence overview is displayed in the right side of the UI (D). For a station and certain components (selected in (B) the operation sequence, with times and cost are shown. 


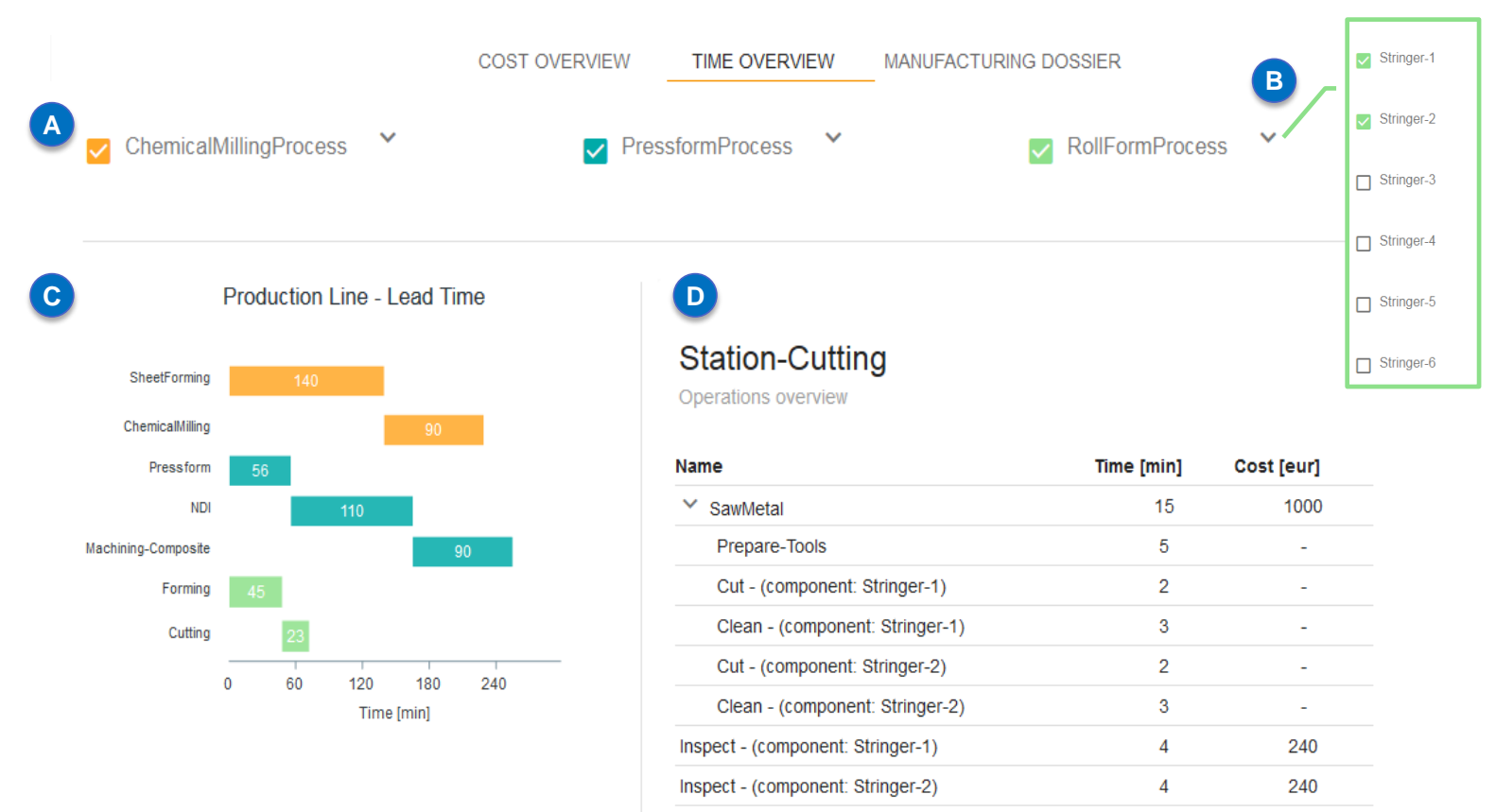

Fig. 10 Results tab of the UI. Note that some operations in (D) do not have a cost because the rate was not defined at sub-operation level.

The above examples show how MAMOT allows to explore production as a discipline in design. However, these examples do not illustrate how MAMOT is integrated within the design process. As a part of future work, MAMOT will be integrated with other design tools using an automated design generator, as described in [22], or an integration environment like $R C E^{* *}$, or both.

To conclude this section, it is pointed out that accurate production data is still in the process of being collected for the validation of the results produced by MAMOT. However, the tool will produce results as accurate as the inputs given. If, for instance, some operations are not described in the ontologies, they cannot be considered. Hence, the estimated time and cost will not be realistic. Nevertheless, this allows to completely separate the knowledge of product and processes from their application.

\section{Conclusions and future work}

This paper has presented the need for modeling aircraft production using knowledge-based engineering since it is expected that it will provide several advantages in comparison with the current methods employed in industry, such as, automation of repetitive tasks, increase of creative design time, reduction in the number and duration of the design iterations and improvement in collaborative design to ultimately reduce development time. Additionally, it is proposed to use semantic web technologies to separate production knowledge and its application, improving the reuse and maintenance of knowledge as well as providing a more flexible and adaptable system. Consequently, the practical problems that arise when implementing the KBE systems, such as elevated cost and time, resistance to change, or confidentiality issues, will also be mitigated.

Besides the suggestion for a new methodology, this paper also introduced the main requirements that should be considered in the development of a new production modeling framework as well as the capabilities that will enable them. From these requirements, the production modeling framework MAMOT has been developed, consisting of three elements: the knowledge module, the assessment engine and the inference engine. The separation between the formalized knowledge and the system execution will result in a more transparent, flexible and adaptable tool. However, this separation of knowledge requires significant work of knowledge formalization. To facilitate that, MAMOT also provides a meta-model that can be easily edited so that different users can customize their ontologies and rules according

**http://rcenvironment.de/ 
to their own production knowledge.

Finally, the paper showed two examples within the production modeling of a fuselage using MAMOT, showing the current capabilities of the tool. Future work includes the formalization of in-depth knowledge to enable more complex SWRL rules involving product geometry, the consideration of transfer operations and shifts in the lead-time graph, the documentation of the results, and the execution of simulations along with experiments to obtain more formalized knowledge or to validate the results.

Despite of the fact that not all the described requirements are completely satisfied yet, this work shows a step forward in the direction of improving the current methods used in the modeling of aircraft production and its connection to design parameters.

\section{References}

[1] Curran, R., Raghunathan, S., and Price, M., "Review of aerospace engineering cost modelling: The genetic causal approach," Progress in aerospace sciences, Vol. 40, No. 8, 2004, pp. 487-534.

[2] Butterfield, J., Mawhinney, P., Crosby, S., Price, M., Curran, R., Armstrong, C., Raghunathan, R., McAleenan, D., and McKeever, C., "An Integrated Approach to the Conceptual Development of Aircraft Structures Focusing on Manufacturing Simulation and Cost." AIAA 5th ATIO and16th Lighter-Than-Air Sys Tech. and Balloon Systems Conferences, 2005, p. 7355.

[3] Geiger, T. S., and Dilts, D. M., "Automated design-to-cost: integrating costing into the design decision," Computer-aided design, Vol. 28, No. 6-7, 1996, pp. 423-438.

[4] Zhou, Y., Li, Y., and Wang, W., "A feature-based fixture design methodology for the manufacturing of aircraft structural parts," Robotics and Computer-Integrated Manufacturing, Vol. 27, No. 6, 2011, pp. 986-993.

[5] Quintana-Amate, S., Bermell-Garcia, P., Tiwari, A., and Turner, C. J., "A new knowledge sourcing framework for knowledgebased engineering: An aerospace industry case study," Computers \& Industrial Engineering, Vol. 104, 2017, pp. 35-50.

[6] Mas, F., Ríos, J., Menéndez, J., and Gómez, A., "A process-oriented approach to modeling the conceptual design of aircraft assembly lines," The International Journal of Advanced Manufacturing Technology, 2013, pp. 1-14.

[7] Verhagen, W. J., Bermell-Garcia, P., van Dijk, R. E., and Curran, R., "A critical review of Knowledge-Based Engineering: An identification of research challenges," Advanced Engineering Informatics, Vol. 26, No. 1, 2012, pp. 5-15.

[8] Reddy, E. J., Sridhar, C., and Rangadu, V. P., "Knowledge based engineering: notion, approaches and future trends," American Journal of Intelligent Systems, Vol. 5, No. 1, 2015, pp. 1-17.

[9] Belie, G., "Non-technical barriers to multidisciplinary optimization in the aerospace industry," 9th AIAA/ISSMO Symposium on Multidisciplinary Analysis and Optimization, 2002, p. 5439.

[10] Zawadzki, P., and Żywicki, K., "Smart product design and production control for effective mass customization in the Industry 4.0 concept," Management and Production Engineering Review, Vol. 7, No. 3, 2016, pp. 105-112.

[11] Pullan, T. T., Bhasi, M., and Madhu, G., "Object-oriented modelling of manufacturing information system for collaborative design," International Journal of Production Research, Vol. 50, No. 12, 2012, pp. 3328-3344.

[12] Wang, J., Chen, H., Liu, C., and Wang, X., "A digital definition method for manufacturing model of aircraft integral panel," Proceedings of the 11th International Conference on Manufacturing Research (ICMR2013), Cranfield University, UK, 19th, 2013, pp. 121-126.

[13] Tan, H., Liu, C., Chen, H., and Wang, J., "An intelligent approach to design three-dimensional aircraft sheet metal part model for manufacture," Proceedings of the 11th International Conference on Manufacturing Research (ICMR2013), Cranfield University, UK, 19th, 2013, pp. 83-88.

[14] Van der Laan, A. H., "Knowledge based engineering support for aircraft component design,” Ph.D. thesis, TU Delft, Delft University of Technology, 2008.

[15] Zhao, X., Verhagen, W. J., and Curran, R., "Estimation of aircraft component production cost using knowledge based engineering techniques," Advanced Engineering Informatics, Vol. 29, No. 3, 2015, pp. 616-632.

[16] Gómez, A., Mas, F., Menéndez, J., and Ríos, J., “A knowledge based application for industrialization design,” Procedia Engineering, Vol. 63, 2013, pp. 318-326. 
[17] Menéndez, J., Mas, F., Servan, J., Arista, R., and Ríos, J., "Implementation of the iDMU for an Aerostructure Industrialization in AIRBUS," Procedia Engineering, Vol. 63, 2013, pp. 327-335.

[18] Sanya, I., and Shehab, E., "An ontology framework for developing platform-independent knowledge-based engineering systems in the aerospace industry," International Journal of Production Research, Vol. 52, No. 20, 2014, pp. 6192-6215.

[19] De Long, D., "Building the knowledge-based organization: How culture drives knowledge behaviors," Centers for Business Innovation-Working Paper, 1997, pp. 1-29.

[20] Gross, D. C., Tucker, W. V., Harmon, S. Y., and Youngblood, S. M., "Fidelity Theory Advances in Distributed Simulation," Summer Computer Simulation Conference, Society for Computer Simulation International; 1998, 1999, pp. 415-420.

[21] Woehler, S., Hartmann, J., Prenzel, E., and Kwik, H., "Preliminary aircraft design for a midrange reference aircraft taking advanced technologies into account as part of the AVACON project for an entry into service in 2028," , August 2018.

[22] Zamfir, A., Jepsen, J., Moerland, E., and Nagel, B., "Development of a Modular Knowledge-Based Model Generator for the Preliminary Aircraft Design Process of the Future," 2018 Aviation Technology, Integration, and Operations Conference, 2018, p. 4005. 